\title{
VALIDASI DATA CURAH HUJAN SATELIT TRMM DAN PERSIANN DALAM ANALISIS DEBIT BANJIR RENCANA DI DAS TELAGA LEBUR
}

\author{
Erni Mulyandari \\ Program Studi Teknik Sipil Fakultas Teknik Universitas Tunas Pembangunan Surakarta \\ erni.mulyandari@lecture.utp.ac.id \\ Herman Susila \\ Program Studi Teknik Sipil Fakultas Teknik Universitas Tunas Pembangunan Surakarta \\ herman.susila@lecture.utp.ac.id
}

\begin{abstract}
Abstrak
Perkiraan debit banjir perlu dilakukan untuk meminimalisasi terjadinya kerusakan di tubuh bendungan, terutamanya di Waduk Telaga Lebur (DAS Telaga Lebur). Perkiraan debit banjir biasanya menggunakan data hujan terukur permukaan (ground data hujan) dari stasiun hujan, akan tetapi di DAS Telaga Lebur data hujan yang tersedia tidak lengkap sehingga perlu adanya alternatif lain untuk memprediksi debit banjir tersebut yaitu dengan menggunakan data hujan TRMM atau PERSIANN dalam mengisi ground data hujan yang tidak ada. Penelitian ini bertujuan untuk mengetahui data hujan satelit yang paling baik (TRMM atau PERSIANN) untuk menentukan debit banjir rencana di lokasi penelitian. Tahap analisis diawali dengan mencari hubungan antara ground data hujan dengan data hujan satelit yang berupa koreksi atau penyesuaian terhadap waktu dan besaran. Penyesuaian terhadap waktu dicari dengan cross correlation, sedangkan penyesuaian terhadap besaran dicari dengan regresi. Tahap analisis selanjutnya adalah menggunakan data hujan satelit yang memiliki korelasi paling baik untuk digunakan dalam analisis perkiraan debit banjir. Hasil penelitian menunjukkan bahwa terdapat hubungan antara ground data hujan dengan hujan satelit TRMM lebih akurat dibandingkan data hujan satelit PERSIANN sehingga prediksi debit banjir untuk kala ulang 2 tahun, 5 tahun, 10 tahun, 20 tahun, 50 tahun, 100 tahun, dan 1000 tahun secara berurutan adalah $11.31 \mathrm{~m}^{3} / \mathrm{s} ; 31.76 \mathrm{~m}^{3} / \mathrm{s} ; 64.68 \mathrm{~m}^{3} / \mathrm{s} ; 114.95 \mathrm{~m}^{3} / \mathrm{s} ; 214.68 \mathrm{~m}^{3} / \mathrm{s} ; 320.55 \mathrm{~m}^{3} / \mathrm{s}$; dan $943.77 \mathrm{~m}^{3} / \mathrm{s}$.
\end{abstract}

Kata kunci: hujan terukur permukaan, hujan satelit, regresi, cross correlation, debit banjir rencana.

\begin{abstract}
Estimated flood discharge needs to be done to minimize damage to the body of the dam, especially in the Telaga Lebur Reservoir. Flood debit estimates usually use surface measured rainfall data from the rainfall station, but in Telaga Lebur Watershed the available rainfall data is incomplete, so there is an alternative to predict the flood discharge using TRMM or PERSIANN rainfall data to filling missing ground rainfall data. This study aims to determine the best satellite rainfall data (TRMM or PERSIANN) to determine the flood discharge plan at the study site. The analysis phase begins by looking for the relationship between ground and satellite rainfall data in the form of corrections or adjustments to time and magnitude. Adjustment for time is sought by cross-correlation, while adjustment for magnitude is sought by regression. The next stage of analysis is to use satellite rain data that has the best correlation to be used in the analysis of flood discharge estimates. The results showed that there was a relationship between the ground rainfall data and TRMM satellite rainfall data more accurately than the satellite PERSIANN rainfall data so that the predicted flood discharge for the return period of 2 years, 5 years, 10 years, 20 years, 50 years, 100 years, and 1000 years is $11.31 \mathrm{~m}^{3} / \mathrm{s} ; 31.76 \mathrm{~m}^{3} / \mathrm{s} ; 64.68 \mathrm{~m}^{3} / \mathrm{s} ; 114.95 \mathrm{~m}^{3} / \mathrm{s} ; 214.68 \mathrm{~m}^{3} / \mathrm{s} ; 320.55 \mathrm{~m}^{3} / \mathrm{s} ;$ and $943.77 \mathrm{~m}^{3} / \mathrm{s}$.
\end{abstract}

Keywords: ground rainfall data, satellite rainfall data, regression, cross-correlation, flood discharge estimation. 


\section{PENDAhuluan}

Waduk Telaga Lebur terletak di Desa Sekotong Tengah, Kecamatan Sekotong, Kabupaten Lombok Barat. Kecamatan Sekotong merupakan salah satu dari sepuluh kecamatan yang ada di Kabupaten Lombok Barat. Waduk ini memiliki luas genangan sebesar 16,3 Ha, CA (Catchment Area) sebesar $10,5 \mathrm{~km}^{2}$, volume tampungan sebesar $1.276 .000 \mathrm{~m}^{3}$. Seiring dengan bertambahnya usia Waduk Telaga Lebur perlu dilakukan analisis terhadap debit banjir yang terjadi untuk mengetahui kemungkinan banjir kala ulang yang ada di waduk tersebut.

Pada kenyataannya, ketersediaan data hujan menjadi hal yang paling penting dalam menghitung besarnya debit banjir di suatu Daerah Aliran Sungai (DAS). Berdasarkan data sekunder yang ada, data hujan ground di lokasi studi adalah Stasiun Hujan Kuripan (19832006) dan Stasiun Sekotong (2012-2015). Oleh karena itu perlu adanya perkiraan data hujan mulai tahun 2007 - 2019 dengan acuan Stasiun Sekotong sebagai alternatif untuk memprediksi banjir. Perkiraan data hujan yang memungkinkan yaitu dengan menggunakan data hujan satelit.Data hujan satelit merupakan data hujan yang didapat melalui penginderaan jarak jauh dengan menggunakan sinar infra merah dan juga gelombang mikro. Data hujan satelit umumnya digunakan untuk memperkirakan iklim, cuaca, dan memungkinkan untuk membantu dalam analisis hidrologi. Data hujan satelit dapat diperoleh dengan cepat melalui internet. Namun sebelum digunakan untuk melakukan analisis banjir, data hujan satelit tersebut perlu disesuaikan terlebih dahulu agar data tersebut dapat dianggap mewakili hujan yang sebenarnya terjadi di lokasi studi dikarenakan data hujan satelit merupakan data hujan yang diukur secara tidak langsung terhadap hujan yang ada di atmosfer.

Penelitian data hujan terukur permukaan dengan data hujan satelit telah banyak dilakukan. Yang Hong, dkk (2009) melakukan penelitian dengan fokus analisis yaitu mendeteksi banjir dan tanah longsor yang merupakan jumlah terbesar bencana alam dengan menggunakan estimasi curah hujan multi satelit berbasis NASA TRMM.

$\mathrm{Li} \mathrm{Li}$ (2009) menganalisis data real-time TRMM yang digunakan untuk memprediksi banjir di lokasi studi kemudian dibandingkan dengan data debit pengamatan.

Vernimmen (2012) menganalisis dan mengoreksi tiga jenis data satelit yaitu TRMM 3B42RT, CMORPH dan PERSIANN dengan grid $0.25^{\circ} \times 0.25^{\circ}$ guna keperluan pemantauan kekeringan.Mamenun (2014) melakukan validasi TRMM terhadap data observasi di wilayah hujan monsun (Lampung, Jawa Timur, Kalimantan Selatan), pola hujan equatorial (Sumatera Utara, Kalimantan Barat), dan pola lokal (Maluku).

\section{METODE PENELITIAN}

\section{A. Lokasi Penelitian}

Waduk Telaga Lebur (DAS Telaga Lebur) berada di Desa Sekotong Tengah, Kecamatan 
Sekotong, Kabupaten Lombok Barat. Waduk ini terletak pada koordinat $\mathrm{X}=394350.00 \mathrm{mT}$ dan $\mathrm{Y}=9028240.00 \mathrm{mS}$. Waduk Telaga Lebur memiliki luas daerah tangkapan air sebesar $10,50 \mathrm{~km}^{2}$. Waduk ini melayani penyediaan air untuk irigasi seluas 210,00 Ha dan air baku sebesar 125,00 Ha. Sumber air pada waduk ini berasal dari sungai.

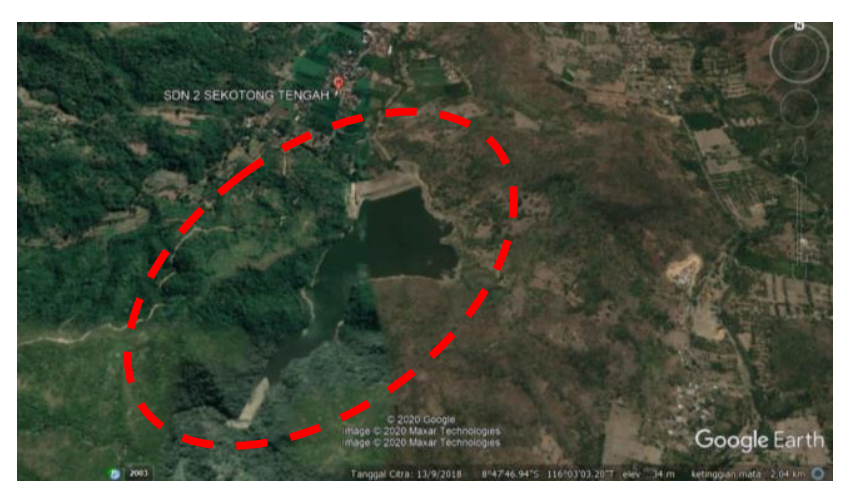

Gambar 1. Lokasi Waduk Telaga Lebur

(Sumber: Citra Satelit Google Maps, 2020)

\section{B. Pengumpulan Data Data yang digunakan} dalam penelitian ini berupa data primer dan sekunder yang dikumpulkan dari beberapa sumber antara lain berasal dari balai wilayah sungai terkait, website data satelit, dan sumber lain yang dapat dipercaya. Adapun data yang nantinya harus dikumpulkan adalah sebagai berikut.

1. Survei lokasi waduk

2. Data hujan harian pos hujan di lokasi terkait

3. Data hujan satelit TRMM dari web NASA (https://giovanni.gsfc.nasa.gov/giovanni)

4. Data hujan satelit PERSIANN yang diperoleh dari web University of California, Irvine (UCI) (http://chrsdata.eng.uci.edu/).
C. Alat yang DigunakanDalam analisis data, peneliti menggunakan alat berupa perangkat lunak sebagai berikut.

1. Arc MAP ver 10.3 untuk digitasi stasiun hujan, membuat poligon Thiessen, digitasi data satelit, menghitung luas area dan panjang sungai.

2. Microsoft Office Excel untuk mengolah data hidrologi dan melakukan perhitungan debit banjir rencana.

3. Microsoft Office Word untuk menyusun laporan penelitian dan jurnal.

\section{Metode Analisis}

Analisis data hujan yang paling penting adalah adanya uji konsistensi. Pada penelitian kali ini diambil metode RAPS untuk melakukan uji konsistensi. Validasi data hujan satelit digunakan 5 metode yaitu Metode Korelasi, BIAS, MBE, RMSE, dan NRMSE.Berdasarkan hasil validasi data hujan tersebut akan diambil kesimpulan data hujan satelit apa yang paling baik digunakan untuk analisis frekuensi.

Analisis frekuensi digunakan dengan 4 macam distribusi yaitu Distribusi Normal, Log Normal, Log Pearson III, dan Gumbel. Untuk selanjutnya dipilih distribusi terbaik dengan menggunakan uji Smirnov Kolmogorov dan Chi-Kuadrat. Dari hasil uji distribusi yang paling baik akan digunakan untuk menentukan besarnya hujan kala ulang.

Hujan kala ulang yang diperoleh akan diubah menjadi hujan jam-jaman dengan metode ABM. Hasil hujan jam-jaman akan digunakan sebagai 
input dalam menghitung debit banjir dengan metode HSS (Hidrograf Satuan Sintetis) Nakayasu dengan Metode Loss CN.

\section{HASIL DAN PEMBAHASAN}

Uji kepanggahan menggunakan metode RAPS terhadap Stasiun Hujan Kuripan dan Stasiun Hujan Sekotong dinyatakan konsisten sehingga kedua data hujan tersebut dapat langsung digunakan dalam analisis selanjutnya. Berdasarkan letak pos stasiun hujan Kuripan dan Sekotong, lokasi yang terdekat dengan Waduk Telaga Lebur adalah Pos Stasiun Hujan Sekotong. Sehingga untuk analisis selanjutnya data hujan satelit yang diperoleh baik TRMM maupun PERSIANN akan dikorelasi dengan Stasiun Hujan Sekotong. Adapun data hujan yang dikorelasi adalah data hujan maksimum dan minimum pada hari dan bulan yang sama di setiap tahunnya mulai dari tahun 2012 - 2015 . Untuk selanjutnya akan dicari besarnya nilai korelasi antara Stasiun Curah Hujan Sekotong dengan TRMM ataupun PERSIAN. Untuk nilai estimasi dengan metode korelasi dipilih nilai yang paling tertinggi sedangkan untuk nilai BIAS, MBE, RMSE, dan NRMSE dipilih nilai yang paling rendah. Hal tersebut sesuai dengan standar setiap metode yaitu untuk Metode Korelasi, semakin tinggi hasil analisis maka akan semakin akurat sedangkan untuk Metode BIAS, MBE, RMSE, dan NRMSE semakin kecil hasil analisis maka akan semakin akurat. Maka berdasarkan hasil analisis diambil kesimpulan bahwa data hujan TRMM (nilai korelasi 0,89) lebih akurat dibandingkan data hujan PERSIANN (nilai korelasi 0,84). Sehingga untuk analisis selanjutnya digunakan data hujan TRMM. Untuk menentukan faktor koreksi yang akan digunakan dalam koreksi data hujan satelit dilakukan dengan mengetahui besarnya parameter a dan b pada persamaan garis antara data hujan ground dengan data hujan satelit TRMM. Pemilihan jenis regresi akan didasarkan padan besarnyanya nilai determinasi $\left(\mathrm{R}^{2}\right)$ tertinggi yang diperoleh dari masing-masing persamaan. Pada penelitian kali ini menggunakan 4 model regresi yaitu Linear, Eksponensial, Logaritmik, dan Power. Adapun hasil persamaan regresi dapat dilihat pada Gambar 2 - Gambar 5 dengan rekapitulasi persamaan seperti pada Tabel 1 berikut ini.

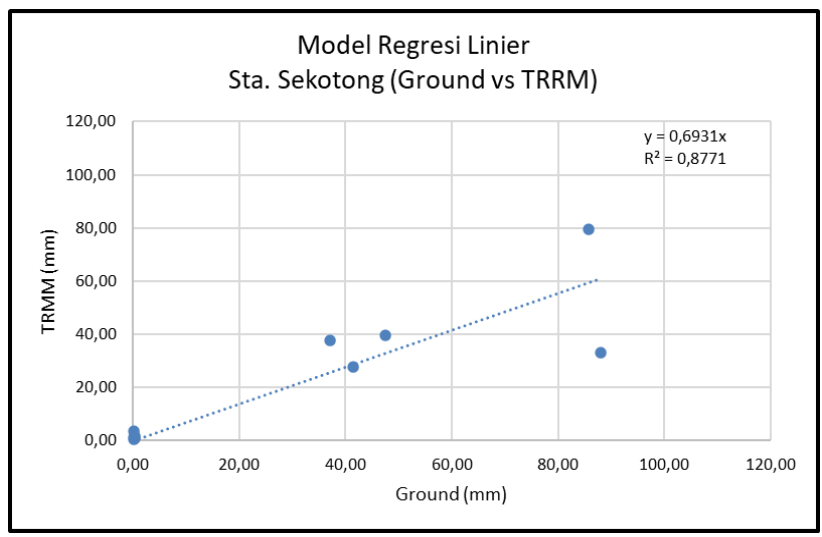

Gambar 2. Model Regresi Linear

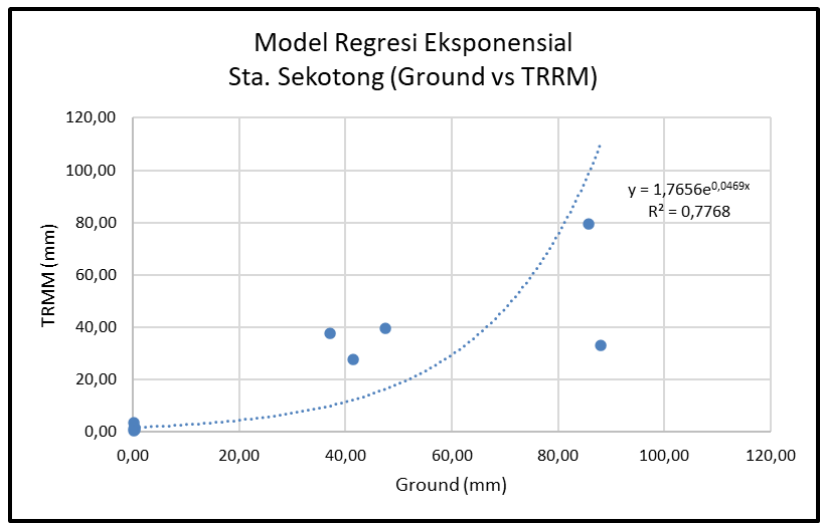

Gambar 3. Model Regresi Eksponensial 


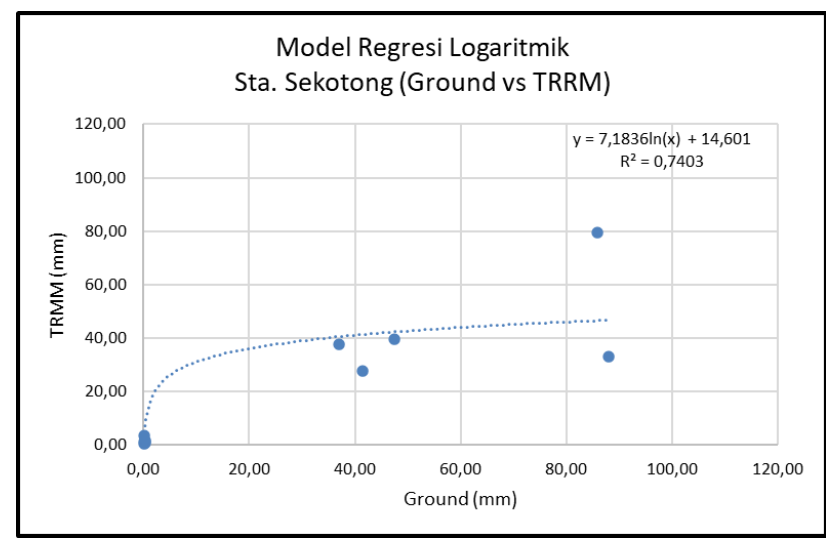

Gambar 4. Model Regresi Logaritmik

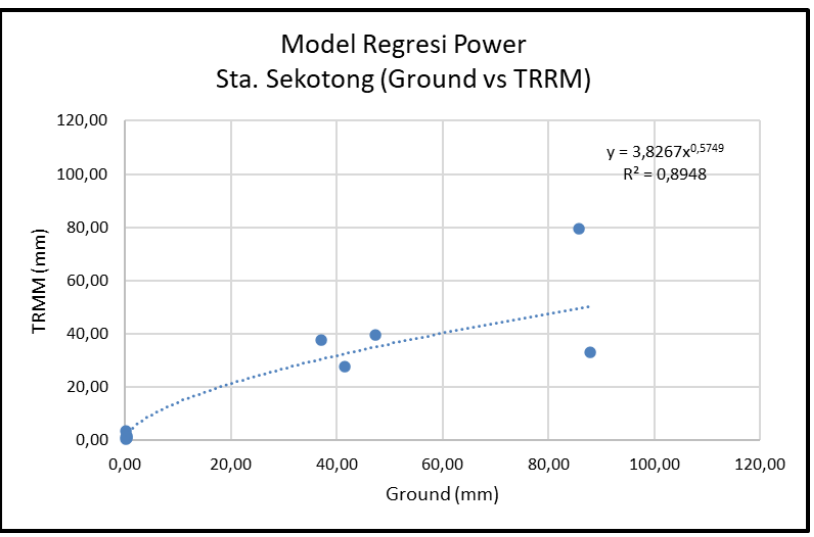

Gambar 5. Model Regresi Power

Tabel 1.

Rekapitulasi Persamaan Regresi dan Determinasi

\begin{tabular}{|c|l|l|c}
\hline No. & \multicolumn{1}{|c|}{ Model Regresi } & \multicolumn{1}{|c|}{ Persamaan Regresi } & $\begin{array}{c}\text { Nilai Determinasi } \\
\left(\mathbf{R}^{2}\right)\end{array}$ \\
\hline 1. & Regresi Linear & $\mathrm{y}=0.6931 \mathrm{x}$ & 0.7745 \\
\hline 2. & Regresi Eksponensial & $\mathrm{y}=1.7656 \mathrm{e}^{0.0469 \mathrm{x}}$ & 0.7768 \\
\hline 3. & Regresi Logaritmik & $\mathrm{y}=7.1836 \ln (\mathrm{x})+14.601$ & 0.7403 \\
\hline 4. & Regresi Power & $\mathrm{y}=3.8267 \mathrm{x}^{0.5749}$ & 0.8948 \\
\hline
\end{tabular}

Berdasarkan nilai determinasi yang dapat dilihat pada Tabel 1, dapat diketahui bahwa model regresi yang terbaik adalah Model Regresi Power dengan nilai determinasi sebesar 0,8948 atau $89,48 \%$.

Untuk selanjutnya, data hujan TRMM harus dikoreksi dengan Model Regresi Power dengan cara menginverskan persamaan tersebut. Adapun hasil inversnya adalah $\mathrm{x}=0.09688 \mathrm{y}^{1.7394}$. Dengan menggunakan persamaan tersebut maka data hujan satelit
TRMM yang akan digunakan untuk menghitung debit banjir rencana dapat dilihat seperti pada tabel berikut.

Tabel 2.

Data Hujan Tahunan dan Maksimum TRMM

\begin{tabular}{|c|c|c|c|c|c}
\hline \multirow{2}{*}{ No. } & \multirow{2}{*}{ Tahun } & \multicolumn{2}{|c|}{ Hujan Tahunan $(\mathbf{m m})$} & \multicolumn{2}{c}{ Hujan Maksimum (mm) } \\
\cline { 3 - 6 } & & TRMM & Koreksi & TRMM & Koreksi \\
\hline 1. & 2007 & 922.41 & 947.08 & 63.36 & 131.92 \\
\hline 2. & 2008 & 763.50 & 671.03 & 62.16 & 127.60 \\
\hline 3. & 2009 & 625.44 & 625.45 & 48.81 & 83.80 \\
\hline 4. & 2010 & 1201.98 & 986.53 & 58.05 & 113.29 \\
\hline 5. & 2011 & 1139.04 & 1302.96 & 95.16 & 267.64 \\
\hline 6. & 2016 & 1748.22 & 2017.42 & 97.14 & 277.41 \\
\hline 7. & 2017 & 1603.68 & 2385.55 & 100.68 & 295.23 \\
\hline 8. & 2018 & 914.07 & 1079.77 & 85.56 & 222.45 \\
\hline 9. & 2019 & 809.10 & 815.27 & 72.69 & 167.53 \\
\hline
\end{tabular}

Dengan menggunakan data hujan dan tersebut maka dapat dilakukan analisis debit banjir. Pada prinsipnya sama yaitu melakukan uji konsistensi terlebih dahulu dengan data hujan gabungan (Kuripan, TRMM, dan Sekotong). Adapun uji konsistensi dengan RAPS menunjukkan bahwa data hujan gabungan konsisten dan bisa langsung digunakan untuk analisis debit banjir. Uji kecocokan dilakukan dengan menggunakan uji Chi Kuadrat (Tabel 3) dan Smirnov Kolmogorof (Tabel 4), berdasarkan hasil pengujian dengan 4 macam jenis distribusi dapat diketahui bahwa Distribusi Log Pearson III yang paling baik digunakan untuk merencanakan hujan kala ulang di DAS Telaga Lebur.

Tabel 3. 
Hasil Uji Chi Kuadrat

\begin{tabular}{|c|l|c|c|}
\hline No & \multicolumn{1}{|c|}{ Uji Distribusi } & $\begin{array}{c}\chi^{2} \\
\text { Chi - Kuadrat }\end{array}$ & Hasil Uji \\
\hline 1 & Distribusi Normal & 32.595 & Ditolak \\
\hline 2 & Distribusi Log Normal & 6.108 & Ditolak \\
\hline 3 & Distribusi Gumbel & 16.108 & Ditolak \\
\hline 4 & Distribusi Log Pearson III & 3.946 & Diterima \\
\hline
\end{tabular}

Tabel 4.

Hasil Uji Smirnov Kolmogorov

\begin{tabular}{|c|l|c|c|}
\hline \multirow{2}{*}{ No } & \multicolumn{1}{|c|}{ Uji Distribusi } & $\begin{array}{c}\Delta_{\max } \\
\text { Smirnov Kolmogorov }\end{array}$ & Hasil Uji \\
\hline 1 & Distribusi Normal & 0.212 & Diterima \\
\hline 2 & Distribusi Log Normal & 0.137 & Diterima \\
\hline 3 & Distribusi Gumbel & 0.148 & Diterima \\
\hline 4 & Distribusi Log Pearson III & 0.070 & Diterima \\
\hline
\end{tabular}

Hujan kala ulang yang didapat untuk selanjutnya akan dibuat hyetograph dengan durasi hujan 5 jam seperti pada Tabel 5.

Tabel 5.

Hyetograph DAS Telaga Lebur

\begin{tabular}{|c|c|c|c|c|c|c|c|}
\hline \multirow{2}{*}{$\begin{array}{c}\text { Td } \\
(J a m)\end{array}$} & \multicolumn{7}{|c|}{ Kala Ulang } \\
\cline { 2 - 8 } & $\mathbf{2}$ & $\mathbf{5}$ & $\mathbf{1 0}$ & $\mathbf{2 0}$ & $\mathbf{5 0}$ & $\mathbf{1 0 0}$ & $\mathbf{1 0 0 0}$ \\
\hline $\mathbf{1}$ & 6.26 & 9.76 & 12.95 & 16.84 & 23.40 & 29.73 & 63.77 \\
\hline $\mathbf{2}$ & 9.31 & 14.51 & 19.27 & 25.05 & 34.81 & 44.22 & 94.85 \\
\hline $\mathbf{3}$ & 51.05 & 79.59 & 105.66 & 137.42 & 190.90 & 242.54 & 520.22 \\
\hline $\mathbf{4}$ & 13.27 & 20.69 & 27.46 & 35.72 & 49.62 & 63.04 & 135.22 \\
\hline $\mathbf{5}$ & 7.41 & 11.55 & 15.34 & 19.95 & 27.71 & 35.21 & 75.51 \\
\hline Total & 87.30 & 136.10 & 180.68 & 234.98 & 326.43 & 414.75 & 889.56 \\
\hline
\end{tabular}

Setelah hyetograph hujan jam-jaman diperoleh maka akan dilakukan analisis banjir rencana dengan menggunakan Metode Nakayasu. Metode ini dianggap paling cocok untuk karakteristik DAS di Pulau Lombok sedangkan untuk kalibrasi hidrograf digunakan perhitungan debit bankfull yang akan dianggap sebagai debit maksumum untuk kala ulang 2 tahunnya.

Adapun hasil hidrograf banjir untuk 7 kala ulang di DAS Telaga Lebur dapat dilihat seperti pada
Gambar 6.

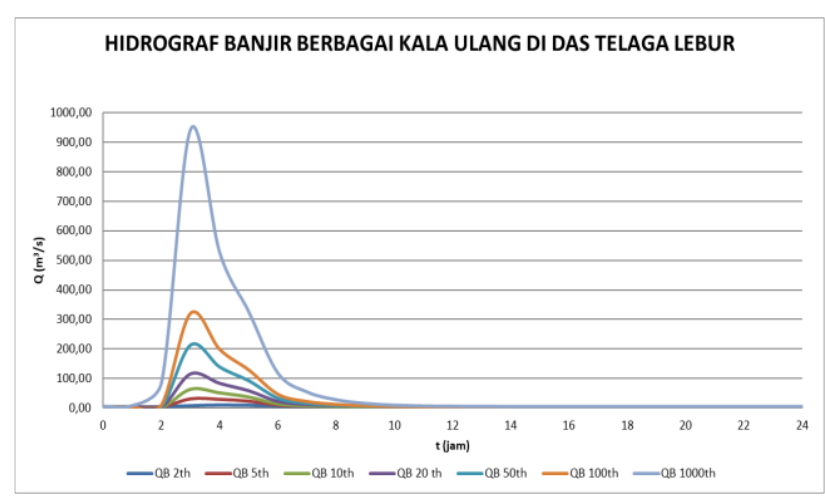

Gambar 6. Hidrograf Banjir Berbagai Kala Ulang di DAS Telaga Lebur

Berdasarkan Gambar 6, dapat diketahui debit maksimum tiap kala ulang dapat dilihat seperti pada tabel berikut.

Tabel 6.

Debit Banjir Maksimum Berbagai Kala Ulang

\begin{tabular}{|c|c|c|c|c|c|c|}
\hline \multicolumn{7}{|c|}{ Debit Banjir Maksimum Kala Ulang $\left(\mathbf{m}^{\mathbf{3}} / \mathbf{s}\right)$} \\
\hline $\mathbf{2}$ th & $\mathbf{5}$ th & $\mathbf{1 0}$ th & $\mathbf{2 0}$ th & $\mathbf{5 0}$ th & $\mathbf{1 0 0}$ th & $\mathbf{1 0 0 0}$ th \\
\hline 11.31 & 31.76 & 64.68 & 114.95 & 214.68 & 320.55 & 943.77 \\
\hline
\end{tabular}

\section{KESIMPULAN/RINGKASAN}

Adapun kesimpulan yang dapat diambil pada penelitian kali ini adalah sebagai berikut.

1. Data hujan satelit yang memiliki hubungan paling kuat dengan data hujan ground adalah data hujan satelit TRMM (Tropical Rainfall Measuring Mission).

2. Besarnya debit banjir di DAS Telaga Lebur untuk kala ulang 2 tahun, 5 tahun, 10 tahun, 20 tahun, 50 tahun, 100 tahun, dan 1000 tahun adalah $11.31 \mathrm{~m}^{3} / \mathrm{s} ; 31.76 \mathrm{~m}^{3} / \mathrm{s} ; 64.68$ $\mathrm{m}^{3} / \mathrm{s} ; 114.95 \mathrm{~m}^{3} / \mathrm{s} ; 214.68 \mathrm{~m}^{3} / \mathrm{s} ; 320.55$ $\mathrm{m}^{3} / \mathrm{s} ; 943.77 \mathrm{~m}^{3} / \mathrm{s}$.

Sedangkan untuk saran yang dapat disampaikan untuk penelitian selanjutnya adalah sebagai berikut. 
1. Penelitian ini hanya menggunakan data hujan harian dari stasiun pengamatan dengan panjang data yang relatif singkat, sehingga bisa dikembangkan untuk daerah lain yang memiliki panjang data hujan harian yang lebih lama.

2. Persamaan regresi yang dihasilkan hanya berdasarkan pada parameter statistik dan belum dikasi berdasarkan fenomena yang ada di atmosfer.

3. Data satelit yang digunakan hanya terbatas pada TRMM dan PERSIANN sehingga bisa dikembangkan untuk data hujan satelit yang lain.

\section{UCAPAN TERIMA KASIH}

Penulis mengucapkan terima kasih kepada Universitas Tunas Pembangunan Surakarta yang telah memberikan dukungan finansial melalui Hibah Penelitian Internal.

\section{DAFTAR PUSTAKA}

Bambang Triatmodjo. 2010. Hidrologi Terapan. Beta Offset. Yogyakarta.
C.D. Soemarto. 1999. Hidrologi Teknik. Erlangga. Jakarta.

Fadholi, A., dkk. 2014. Pemanfaatan Model Weather Research and Forecasting (WRF) dalam Analisis Cuaca terkait Hujan Lebat Batam 30-31 Januari 2011. Surabaya : Jurnal Fisika Dan Aplikasinya Volume 10, Nomor 1 Januari 2014

Mamenun, Pawitan, H., Sophaheluwakan, A. 2014. Validasi dan Koreksi Data Satelit TRMM pada Tiga Pola Hujan di Indonesia. Jurnal Meteorologi Dan
Geofisika Vol. 15 No. 1 Tahun 2014 : 1323

Marzuki, et al. 2013. Raindrop axis ratios, fall velocities and size distribution over Sumatra from 2D-Video Disdrometer measurement. Atmospheric Research 119 (2013) 23-37. doi:10.1016/j.atmosres.2011.08.006

Prasetia, R., As-syakur, A.R., Osawa, T. 2013. Validation of TRMM Precipitation Radar satellite data over Indonesian region. Theor Appl Climatol (2013) 112:575-587. DOI 10.1007/s00704-012-0756-1

Putu PW, Nurhastuti AR. 2016. Analisis Kondisi Atmosfer pada Kejadian Hujan Lebat di Ambon Tanggal 29 Juli 2016 . Proseding Seminar Nasional Fisika dan Aplikasinya, Bale Sawala Kampus Universitas Padjadjaran, Jatinangor.

SNI 2415-2016, Tata Cara Perhitungan Debit Banjir Rencana.

Su, F., Hong, Y. Lettenmaier, D.P. 2007. Evaluation of TRMM Multisatellite Precipitation Analysis (TMPA) and Its Utility in Hydrologic Prediction in the La Plata Basin. Journal of Hydrometeorology Volume 9

Suripin. 2004. Sistem Drainase Perkotaan yang Berkelanjutan. Andi Offset. Yogyakarta.

Vernimmen, R.R.E., Hooijer, A., Mamenun, Aldrian, E., van Dijk, A.I.J.M. 2012. Evaluation and bias correction of satellite rainfall data for drought monitoring in Indonesia. Hydrol. Earth Syst. Sci., 16, 133-146, 2012. www.hydrol-earth-systsci.net/16/133/2012/. doi:10.5194/hess16-133-2012 